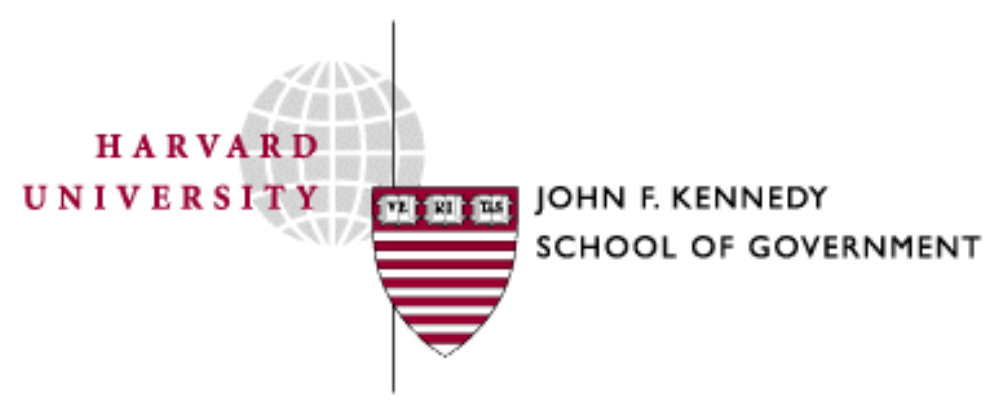

Faculty Research Working Papers Series

What Is and Is Not Wrong with Enhancement?

Frances Kamm

John F. Kennedy School of Government

Harvard University

May 2006

RWP06-020

This paper can be downloaded without charge from:

http://ksgnotes1.harvard.edu/Research/wpaper.nsf/rwp/RWP06-020

or

The Social Science Research Network:

http://ssrn.com/abstract=902372

The views expressed in the KSG Faculty Research Working Paper Series are those of the author(s) and do not necessarily reflect those of the John F. Kennedy School of Government or Harvard University. Copyright belongs to the author(s). Papers may be downloaded for personal use only. 


\title{
WHAT IS AND IS NOT WRONG WITH ENHANCEMENT? ${ }^{1}$
}

\author{
F. M. Kamm
}

(C) F. M. Kamm 2006. All rights reserved.

\begin{abstract}
:
This article examines the arguments concerning enhancement of human persons recently presented by Michael Sandel. In the first section, I briefly describe some of his arguments. In section two, I consider whether, as Sandel claims, the desire for mastery motivates enhancement and whether such a desire could be grounds for its impermissibility. Section three considers how Sandel draws the distinction between treatment and enhancement, and the relation to nature that he thinks each expresses. The fourth section examines Sandel's views about parent/child relations and also how enhancement would affect distributive justice and the duty to aid. In conclusion, I briefly offer an alternative suggestion as to why enhancement may be troubling and consider what we could safely enhance.
\end{abstract}

Should we enhance human performance? There are at least two types of enhancement. In the first, we make it the case that more people are above the current norm in ways that many people are already quite naturally. For example, we might increase intelligence so that many more people who would otherwise be only moderately intelligent function as well as those few who are geniuses. In the second form of enhancement, we introduce improvements that no human being has yet evidenced—for example, living to be two hundred years old and healthy. The question of whether we should engage in either type of enhancement has arisen recently within the context of human genetics. Here one 
generation would probably modify the next. However, enhancement can also occur by way of drugs or intensive training and be done by a person to himself or to another.

Michael Sandel has recently argued that there is a moral problem with both types of enhancement regardless of the way in which they would be brought about, even if there were agreement (which there often is not) that the changes would be improvements, that they were safe, and they were fairly distributed among socioeconomic groups (Sandel 2004). Sandel's discussion is worth significant attention both because he is a member of the President's Council on Bioethics and because it expresses in compact form, readily available to the general public, some prominent concerns. In this essay, I shall present what seem to me to be the important components of Sandel's argument and then evaluate it.

\section{Sandel's Views}

Sandel thinks that the deepest objection to enhancement is the desire for mastery that it expresses. He focuses especially (but not exclusively) on the attempt of parents to enhance their children, whether by genetic manipulation, drugs, or extensive training. He says:

the deepest moral objection to enhancement lies less in the perfection it seeks than the human disposition it expresses and promotes. The problem is not that parents usurp the autonomy of a child they design. The problem is in the hubris of the designing parents, in their drive to master the mystery of birth...it would disfigure the relation between parent and child, and deprive the parent of the humility and 
enlarged human sympathies that an openness to the unbidden can cultivate. (Sandel 2004, 57)

And he thinks:

the promise of mastery is flawed. It threatens to banish our appreciation of life as a gift, and to leave us with nothing to affirm or behold outside our own will. (Sandel 2004, 62)

However, he believes this objection is consistent with the permissibility and even the obligation to treat illnesses by genetic modification, drugs, or training. He is, therefore, arguing for a moral distinction between treatment and enhancement. He says (Sandel 2004, 57): "Medical intervention to cure or prevent illness or restore the injured to health does not desecrate nature but honors it.” He also thinks parents must "shape and direct the development of their children...,” but he thinks there must be an equilibrium between "accepting love” and "transforming love.”

Among the bad effects of mastery, he identifies the increasing responsibility that we must bear for the presence or absence of characteristics in ourselves and others and the effects this may have on human solidarity. The first point is concerned with the fact that we will no longer be able to say that lacking a perfection is a matter of luck, something outside our control. We might be blamed for not improving ourselves or others. The second point is (supposedly) related to this. Sandel believes that the more our characteristics are a matter of chance rather than choice, "the more reason we have to share our fate with others” (Sandel 2004, 60). He goes on:

Consider insurance. Since people do not know whether or when various ills will befall them, they pool their risk...insurance markets mimic solidarity only insofar as 
people do not know or control their own risk factors... Why, after all, do the successful owe anything to the least-advantaged members of society? The best answer to this leans heavily on the idea of giftedness... A lively sense...that none of us is wholly responsible for his or her success makes us willing to share the fruits of our talents with the less successful. (Sandel 2004, 60)

\section{Desire for Mastery}

A. Let us first clarify the nature of Sandel's objection to enhancement based on the desire for mastery over life processes. Note that it implies that if (both types of) enhancements were occurring quite naturally, without our intervention, Sandel's objection to enhancement would not be pertinent. Indeed, interfering with the natural enhancing changes would itself require mastery over life processes, and so Sandel's objection might pertain to this. It is also important to keep in mind several distinctions. Actual mastery is different from the desire for it. We could achieve and exercise mastery over nature as a side effect of doing other things, without desiring it. This might be acceptable to Sandel. Suppose we did desire mastery, however. We could desire it as a means to some other end (e.g., achieving such good aims as health, beauty, or virtue) or we could desire it as an end in itself. So long as we desire it as a means to other things considered good, it is clearly wrong for Sandel to conclude that desire for mastery will “leave us with nothing to affirm or behold outside our own will” (Sandel 2004, 62). Even if mastery were desired as an end in itself, this need not mean that it is our only end, and so we could still continue to affirm other good aims (such as virtue, health, etc.) as ends 
outside our own will. I shall henceforth assume that if we desire mastery, it is as a means to good ends, as this seems most reasonable.

Such a desire for mastery is not inconsistent with an openness to the unbidden that Sandel emphasizes (Sandel 2004, 56), if the unbidden means just "those things that come without our deliberately calling for or causing them.”² For if many good things were to come without our deliberately intervening to bring them about, presumably we would be happy to have them and not regret that they came about without our deliberately bringing them about. Such a form of openness to the unbidden does not, however, necessarily imply a willingness to accept whatever comes even if it is bad. Sometimes people are also unwilling to accept things that merely differ from their preferences or that are not as good as they might be, though the things are not necessarily bad. One or all of these forms of being closed to the unbidden may be what Sandel is concerned with, as he speaks of enlarged human sympathies resulting from an openness to the unbidden.

So far, I have been distinguishing various attitudes and states of mind that might be involved in a desire for mastery. Suppose some form of the desire for mastery and nonopenness to the unbidden were bad. The further question is whether there is any relation between having even a bad attitude and the impermissibility of enhancing conduct. As noted above, even Sandel supports the efforts to find certain treatments for illnesses. But seeking treatments for illnesses by manipulating the genome typically involves desiring mastery as a means, not being open to all things unbidden, and attempting to master the mystery of birth. Hence, Sandel may think that while there is something bad per se about desiring mastery even as a means, not being open to the unbidden, and attempting to master the mystery of birth, these bads can be outweighed by 
the good of curing diseases (if not by the pursuit of enhancements). Alternatively, he may believe that when the unbidden is very horrible - not a gift, even in disguise - not being open to the unbidden is not bad at all. If he believes these things, the question then is why enhancements cannot outweigh or transform the negative value of seeking mastery and not being open to the unbidden in the same way that he thinks that treatments outweigh or transform it. ${ }^{3}$

There is a further, deeper problem about the relation between having bad dispositions and the impermissibility of conduct. For suppose that desiring mastery as one's sole end in life is a bad desire to have. Suppose a scientist who works on finding a cure for congenital blindness is motivated only by such a bad desire for mastery. Does this make his conduct impermissible? Presumably not. The good of treating diseases still justifies the work of the scientist even when his primary aim is not that disease be treated but rather to achieve mastery. This is a case where there may be a duty to do the work. However, even when the act one would do would produce a good that is not one's duty to produce, I think the act can be permissible independent of one's intentions or disposition in doing it. So suppose several people could be saved only if you do an act that has a high probability of killing you. It is not typically your duty to do such an act, though it could be worthwhile to do it. If the only reason you do it is to make those who care about you worry, this alone will not make saving the people impermissible. More generally, it has been argued, the intentions and attitudes of an agent most often reflect on the agent's character but do not determine the permissibility of his act (Scanlon 2000; Thomson 1990). ${ }^{4}$ 
Sometimes, we think that an act is permissible only if it aims to satisfy a certain desire in an agent who does the act. For example, suppose we set aside scarce resources for a musical performance in order that those who desire pleasure from music shall have some. If someone's only intention in going to a concert is to mingle with other people, this is an indication that he has no desire for music per se. Hence, it is an indication that an end which justified the use of scarce resources for musical performances will not be achieved. So, if this agent should not go to the concert, it is not because of his intention per se, but only because the intention is an indication that some effect that justifies funding concerts (pleasure from music) will not come about.

Now, suppose someone has a bad aim (e.g., to show off) in doing something otherwise permissible, such as chewing gum. It might be appropriate for him to, in a sense, be punished for the bad aim with which he would chew the gum, by making it impermissible for him to chew the gum. This, of course, is not just any punishment. It specifically makes it the case that his bad aim is not efficacious. But if the achievement of an important good for others or the performance of a dutiful act (e.g., not harming someone) is at stake and this can justify the act, it would not be appropriate to require someone to forgo the act as a way of making his bad aim inefficacious. That would be to punish others for the agent's bad attitude.

If intentions and dispositions do not generally affect the permissibility of acts, and if Sandel were right that "the deepest moral problem with enhancement" is "the human disposition it expresses," then the deepest moral problem would provide no grounds at all for thinking that acts seeking enhancement are morally impermissible (Sandel 2004, 57). We will have to decide whether particular enhancements are permissible independently 
of the aims, attitudes, and dispositions of agents who act. Among the factors we might consider are the goods that would be brought about and the bad effects that might also occur. It is true that if the good outweighs the bad, then it is possible for a rational agent to have as his aim the pursuit of the good, rather than the (supposedly) bad aim of seeking mastery above all else. But still it is the evaluation of objective goods and bads, rather than the agent's aims, dispositions, or desires that play a role in accounting for the permissibility of producing the enhancement. If the only possible aim of a rational agent in seeking a particular change were to seek mastery as an end in itself, then presumably this would be an indication that no good effect achieved by the change would be able to justify the act.

Furthermore, we need not be restricted to a consequentialist weighing of goods and bads in accounting for the permissibility of an act of enhancement. Individual rights may be at stake and the causal role of bad effects (e.g., whether they are side effects or necessary means to good effects) could be morally relevant to permissibility of an act, even if agent's intention and disposition are not.

In connection with the effects of enhancing, there is a further point that Sandel makes, for he is concerned not only with the disposition that enhancement expresses but with "the human disposition it ....promotes." Promoting the disposition to seek mastery could be an effect of seeking enhancements, and we have said that the effects of acts can be relevant to their permissibility even if the attitudes of agents who perform the acts are usually not. Indeed, considering the disposition as an effect helps us understand that when Sandel says that "the deepest moral problem with enhancement is the human disposition it expresses,” he may not so much be giving an explanation of the wrongness 
of acts of enhancement as simply focusing on the bad type of people we will be if we seek mastery. ${ }^{5}$ But why would we be bad people if we have the disposition to seek mastery as a means, if this disposition always led to permissible acts, and, furthermore, the disposition always led us to act for the sake of the good effects that make the acts permissible because they make it permissible? (Such persons will be very different from the scientist described above who did not care about the good effect that justified his act [i.e., treating disease] but only about mastery.) Sandel's account implies that even people with such a disposition to mastery could be worse people in virtue of the disposition, and I do not believe this is true.

Perhaps even such a disposition, not in itself bad, could be bad to have, if it leads us to focus on certain types of acts to the exclusion of other worthwhile activities. Consider an analogy. An artist who is always seeking to improve her paintings. She never rests content with just appreciating her own and other people’s great works. Other people may have a better appreciation of great masters that she lacks. Hence, her worthwhile aim interferes with other worthwhile aims. But it is not clear that her way of responding to value-by trying to create more of it-is inferior to an admittedly good alternative way of appreciating valuable things that already exist. And in some people, these two approaches to value may be combined to one degree or another. So the dispositions to enhance and to appreciate goods already present may be combined.

B. I have considered the relation between the permissibility of acts and the intentions and dispositions related to mastery that produce them and that are produced by them. It might be suggested that acts themselves can have meaning as well as being the result of 
intentions and followed by consequences. ${ }^{6}$ Perhaps some reason for an act's being permissible or impermissible is given by what it means or expresses because we should not "say" certain things by our acts. Sometimes, meaning can be due to the intention of the agent, but it has been argued by some that it can also be due to context and to the properties of the act itself. If the meaning of an act can be affected by an agent's intention, and meaning is relevant to permissibility, this still does not show that intention per se is relevant to permissibility, but only that the meaning of the act is relevant to permissibility. Consider a situation in which, it has been said, context, not intention, determines meaning. For example, suppose that in the United States, selecting a male rather than a female child to balance a female child one already has means no more than that one is in balancing genders. That is, with respect to the act's meaning, the context would "drown out" an agent's intention if the parent is actually choosing to have a male child in order to avoid having what he believes is another inferior being in his family. Is his intention, which we shall suppose no one will ever know of, a reason for his act being impermissible? As I understand those who are concerned with an act's meaning, they will have no reason to think it is.

Now, suppose that, in a case where intention determines an act's meaning, no one will understand what an act means because no one knows the intention. It is not clear that the act's actual meaning, as opposed to people's interpretation of its meaning, can be a reason for its impermissibility. Where a bad intention determines meaning and people will find out about the intention, this still does not imply that there is good enough reason not to do the act. For example, suppose parents want good educations for their children, but only as a means to their own social climbing. When the children understand this, they 
will get the message that their parents see them as mere tools. But, of course, despite their parents' beliefs, they are not mere tools, and whatever the parents' intentions, the parents do have a duty to give their children a good education. If it is clear that the children will understand their parents' view of them if and only if the parents give them the education and this understanding will be psychologically very harmful to them, then this must still be weighed against the good of their being educated.

The specific immoral meaning that some think enhancement has, and the immoral message some think it sends, is that the unenhanced have less intrinsic worth than others, where presumably this implies that they do not have equal moral status just in virtue of being persons. (Call this Message 1. Notice that concern about this message could also apply to nongenetic methods of enhancement, such as education and exercise.) Message 1 is to be distinguished from a message that says that some properties are not as good for people to have as other properties. (Call this Message 2.) Presumably, expressing Message 2 is not immoral if some properties are better than others. This is because we can show our concern for someone of equal intrinsic worth by trying to give him properties that it will be better for him to have.

I think that it is highly unlikely that enhancement could carry the immoral Message 1. This is because enhancement is to be done to individuals who are already within the normal range of properties typical of the species. Such people are far less likely to be thought to lack the equal moral status that persons have just in virtue of being persons. ${ }^{7}$ By contrast, those people who would be improved by being given treatments are more likely to be in danger of being mistakenly thought to lack such equal moral status, for they fall below the norm. Yet this is, presumably, not a strong reason against 
treating them. We should cure blindness by drugs or surgery or genetic means because sightedness is good for persons, and because blind persons as much as any persons are worthy of care.

C. I have been focusing on the intentions and actions of individuals and whether their acts of enhancement could be made impermissible by their intentions and dispositions, and the meaning of their acts. One reason why I have discussed the intentions and dispositions of individuals is that Sandel seems to be concerned with why individual parents might seek enhancement in their offspring. Furthermore, one way to conceive of the dispositions and aims of a society is as the sum of the dispositions and aims of the majority of people in it or of its typical members. ${ }^{8}$ It is possible, however, that one would not be concerned if some individuals did certain types of acts from certain dispositions, unless there were collective action, in the sense that a good part of the society were acting in this way, perhaps in unison. Indeed, Sandel has said that he is concerned with social practices and that he thinks that these are constituted, in part, by dispositions as well as acts. ${ }^{9}$ For example, we now have a social practice of parenthood the value of which is constituted, in part, by a disposition to love whatever child comes unbidden and not to predetermine its identity. We now have competitive sports practices the value of which is constituted, in part, by excellences in the skillful exercise of natural gifts. If we pursue enhancements, Sandel thinks, we will corrupt and even eliminate these valuable practices.

Consider how this might happen. If the current practice of parenthood is defined so as to include an openness to the unbidden, then the intention to seek mastery as a 
means will indeed eliminate the current practice. The question, however, is whether a new practice—which might include the disposition to seek mastery in order to improve children for their own sake-is an even more valuable social practice than the older one. One measure would be its effects on children's lives, parent-child relations, etc. (This is an issue I consider in section IV.A. below). I have already argued that having the disposition to seek mastery as a means to good need not be a bad characteristic of persons in itself. But if the means chosen to the good effect, prompted by the good disposition, were bad, there would still be a problem. For example, Sandel mentions the possibility that the practice might involve selecting mates on the basis of their potential for producing children of certain types. But the problem with doing this lies in the inappropriate way it treats potential mates, for relations between adults who seek to be mates should be based primarily on love between them, as a response to their noninstrumental personal characteristics. So impermissible behavior between adults could be involved if this means to achieve mastery were chosen.

In the case of sports, one of Sandel's concerns is that when athletes enhance their physical strength as a way to win competitions, we have a practice that is no longer about exercising skill but about whose body mass can fell an opponent. Here, I would say the problem is that a good aspect of our current practice is not replaced by anything else of value in a new practice. But no one should argue for "body enhancing changes" that have overall bad effects. Sometimes Sandel claims that athletes' eating large quantities of muscle-building substances as a component of the new practice is not in itself an impermissible act; the problem is that the focus on body mass eliminates a practice that relies on the use of valuable skills. But sometimes Sandel claims that in making their 
bodies massive, athletes are degrading themselves. If this were so, then, I would argue, the new practice would involve impermissible means as well as no valuable outcome.

My conclusion is that whether we are concerned with individuals and individual acts or with social practices, we shall have to focus on whether outcomes are valuable and can help justify acts or practices, whether means are permissible, and whether dispositions to mastery as a means to goods are inconsistent with being good people. Emphasizing social practices merely because the identity conditions of a social practice (as a matter of definition) include effects, means, and dispositions will not alter the basic terms of our evaluative analysis from what they are when we consider individual acts and individual character.

\section{Treatment versus Enhancement}

One of my conclusions so far is that we should look to such things as the properties of our acts (possibly including their meaning) and their effects, rights involved, and the required causal role of bad effects in producing the good, rather than to the dispositions and intentions of agents per se, to decide whether acts of enhancement are wrong. Hence, the disposition that Sandel identifies as a primary moral problem with enhancement has nothing to do with whether acts producing enhancements are right or wrong. However, one might rephrase Sandel's objection so that it does bear on the permissibility of acts. One might argue that the goods achievable by enhancement do not justify a causal role for such bad means as people uncovering the mysteries of birth or mastering nature (whether they desire these or not), rather than letting nature "give” us whatever "gifts" it will. ${ }^{10}$ Only the goods of treatment justify such means. (Similarly, one might argue that a 
causal role for such bad means, independent of people's disposition, undermines the worth of a social practice that includes them.)

There are two problems with rephrasing in this way. First, as I suggested above, it may not be true that people's mastering nature, uncovering the secrets of life, and trying to improve what comes in life are bad means.. If they are not bad, then we do not have to show that there are great goods at stake that outweigh the bad, in order to permissibly engage in these activities. Second, if mastering nature were bad, one would have to show not only that the goods of enhancement are not as important as the goods of treatment but that they are not good enough to outweigh or transform the bad aspects of mastery.

There are several possible routes to showing that the goods of enhancement are not as important as the goods of treatment. One is the idea of diminishing marginal utility, according to which the benefit someone gets out of a given improvement in his condition decreases the better off he is. Hence, we do more good if we help those who are worse off than if we help those who are already better off. A second route is the view that there is greater moral value in helping people the worse off they are in absolute terms, even if we produce a smaller benefit to them than we could to people better off. This is known as prioritarianism. A possible third route is to distinguish qualitatively between what some call harmed states and merely not being as well off as one might be but not badly off in absolute terms (Shiffrin 1999). All these analyses will apply only if those to be treated are worse off than those to be enhanced. However, this may not always be true. For example, some illnesses produce states that are less bad than, or equal to, being at the low end of a normal range for a property. Further, none of these routes to comparing the ends of enhancement and treatment shows that enhancements are not in themselves great 
enough goods to justify mastery as a means, even if enhancements are not as important as treatment. They also do not rule out that providing enhancements might be endorsed as a means to achieving some treatments. That is, suppose it is only if we are much smarter than we currently are that we will find a cure for terrible illnesses quickly. Then the importance of finding treatments could be transmitted to the enhancement of intelligence. (Of course, not all means are permitted to even justified ends. So if mastering nature to produce enhancements were sufficiently intrinsically objectionable, it might not be permissible to use the only available means to acquire treatments.)

At one point, Sandel tries to draw the distinction between treatment and enhancement by claiming that "medical intervention to cure or prevent illness...does not desecrate nature but honors it. Healing sickness or injury does not override a child's natural capacities but permits them to flourish” (Sandel 2004, 57). The assumption behind the first sentence is that nature is sacred and should be honored. When Sandel claims that curing and preventing illness do not desecrate nature, he implies that enhancement is a problem because of the sort of relation we should have to nature, as if this could be a source of moral imperatives in addition to our relations to other persons. But should we believe this? Cancer cells, AIDS, and tornadoes are all parts of nature. Are they sacred and to be honored? The natural and the good are distinct conceptual categories and the two can diverge: the natural can fail to be good and the good can be unnatural ( art, dams, etc.). ${ }^{11}$ However, it is an important claim made by some that when there are goods in nature, they can indeed be sources of moral imperatives in addition to our relations to persons. By this they mean that independent of their effects on people, certain natural goods give us reasons to protect or promote them. For example, a great 
oak or the Grand Canyon may give us reasons to protect it even if no persons were favorably affected by this. Furthermore, recognizing their worth means not supplanting them with some things of inferior worth that may be good for people, such as parking lots.

How does this claim—call it the Independent Worth of Nature Claim—bear on not enhancing people? I do not think it serves as any support for the idea that there is a duty to nature not to engage in enhancement. First, it does not imply that, insofar as a "gift" in a person is a good of nature, what is a "gift" should be determined independently of its effect on people (i.e., independently of what is good for, or what is the good of the person). (So, if a person were turning into a magnificent oak, this would not be gift because it is not good for the person, and we should act to prevent this transformation.) Second, the Independent Worth of Nature Claim does not imply that we may not enhance, supplement, or even transform the goods of nature with genuine additional or superior goods.

Now consider the idea embodied in the second sentence of the Sandel quote, that healing honors nature by permitting natural capacities to flourish rather than overriding them. We would clearly be overriding people's natural capacities if we enhanced their immune system (by genetic means or immunization) so that they were able to resist illnesses that they could not naturally resist. Is doing this impermissible because it does not honor nature? Surely not. Suppose nature was sacred and to be honored. We would clearly be overriding its dictates by making people able to resist (by immunization) illnesses that they could not naturally resist. Is doing this impermissible because it does not honor nature? Surely not. 
And indeed, Sandel has said ${ }^{12}$ that such enhancement of natural functioning in order to combat illnesses is to be understood as part of treatment and is not the sort of enhancement he opposes. This may be because overriding natural capacities leads to treatment (or prevention) that does not itself override natural capacities but permits them to flourish.

The position expressed by this view might be illuminated by the following diagram, where "E" stands for enhancement and "T" for treatment.

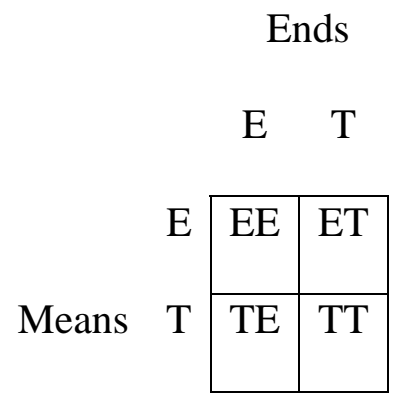

Figure 1

Enhancement can be used to refer to ends or to means. In the immune enhancement, we could enhance people as a means to stopping illness that interferes with natural gifts (ET).. But a way to treat Alzheimer’s disease might also involve increasing general memory power enormously simply as a way to prevent eventual dementia. Here overriding natural capacities to prevent an illness that interferes with natural capacities does not merely allow those natural capacities to flourish. It overrides by supplementing them. So Sandel might see this not as a form of ET, but rather as EE.. He might also object to a more indirect route to stopping Alzheimer’s disease, namely increasing intelligence of scientists so that a cure could more easily be found.) He objects to EE and possibly TE when one treats an illness one would otherwise ignore just because it also enhances (in a way that is not intermediate to further treatment). 
Treatment, even ET, is commended by Sandel because it permits some natural capacities to flourish by eliminating one impediment to them, namely illness. Why would it not honor nature to interfere with other impediments. That is, might Sandel's view be better expressed as the view that we may permissibly override and not honor nature when we get rid of the things in nature that interfere with the other parts of nature that are its gifts (i.e., good things)? If this is so, then Sandel's position would not rule out dramatically lengthening the human life span and preventing the aging process. This involves getting rid of things that are normal and not illnesses, so that they do not impede the exercise of natural gifts that we have had all our lives. Yet most people would consider this a radical enhancement. (And, indeed, this seems in some respect (lifelengthening) like a form a form of EE (in Figure 1).) So, Sandel's original objection to enhancement, that it interferes with gifts that nature has given someone rather than allowing them to flourish, is not always true. It is not true, in some forms of ET and some forms of EE (such as life-lengthening). But sometimes his original objection is true of treatments, as in increasing memory power to stop Alzheimer’s.

For another example, suppose that a child's natural gifts are those of a Down's syndrome child and we seek to supplement these and provide greater gifts than nature provided by changing the child's genome? This would change or add to natural capacities, not merely permit them to flourish. Yet, presumably, Sandel would want to classify this with allowable treatment rather than enhancement because it compensates for a defect. This form of treatment, which involves changing and supplementing nature's gifts with new ones, rather than curing or preventing conditions that interfere with gifts, raises the more general question of why appreciation of nature’s gifts requires limiting 
ourselves to them. We can appreciate what is given and yet supplement it with something new.

There are three primary conclusions of this section so far. First, Sandel's attempt to draw a distinction between treatment and enhancement, based on the allow natural capacity to flourish/override natural capacity distinction, does not seem successful. Second, on one interpretation of how he draws the treatment/enhancement distinction, Sandel's objection to enhancement does not rule out maintaining natural gifts (that would otherwise wither) throughout a greatly extended human life span. Third, we would need much more argument to show that there is some duty owed to nature that we offend against when we change natural capacities and that it is our relation to nature rather than to persons that should be a primary source of concern with enhancement.

Consider an alternative way to draw the treatment/enhancement distinction suggested by P. H. Schwartz. ${ }^{13}$ We treat when we eliminate a dysfunction, not merely prevent anything that interferes with nature's gifts. Dysfunction is an interference with healthy human life, which involves the normal, proper functioning of the human being. The normal, proper functioning of a human being or its parts is the functioning that contributes to survival and reproduction to a degree that does not fall too far below the mean for individuals of the same age and gender. (Possibly, if we alter a genome to add to a Down's syndrome child's gifts, we might be seen to compensate for the dysfunction that originally interfered with normal development.) Schwartz thinks that we should value healthy human life and that fixing dysfunction (i.e., treating the failure of a part to contribute to survival and reproduction to a degree that does not fall too far below the mean for individuals of the same age and gender) has “superior moral status” to 
modifying normal functioning (enhancing), because it alone has “a virtue of accepting the normal” and avoiding the implied rejection of normal human life (Schwartz 2005, 6).

Despite drawing the treatment/enhancement distinction in this way, and identifying treatment as morally superior in at least one way to enhancement, Schwartz thinks there is "no need to treat dysfunctions that are valued by their bearers (such as infertility in some)” and no rule against modifying people so as to produce valued dysfunctions (e.g., infertility by vasectomy). Hence, on his view, the way in which treatment is morally superior to enhancement—by accepting the normal—can be overridden by other ways in which not treating or even producing dysfunction can be morally superior to treatment (e.g., by providing people with things they value). ${ }^{14}$

Let me raise the following concerns with Schwartz's analysis of treatment and enhancement.

(a) First, it draws the treatment/enhancement distinction by relativizing the normal to “the mean for one's age and gender.” Hence, what would ordinarily be thought of as dysfunctions are perfectly normal. For example, it is normal for brain cells to die as we age, heart muscle to atrophy, and joints to wear out. So, it turns out on Schwartz's account that intervening to eliminate such conditions, for example, by providing drugs or doing surgery, is not treatment but rather enhancement. (Only dealing with abnormal dysfunctions would be treatment.) If these are enhancements, then undoing similar normal dysfunctions so that people have radically longer life spans with continuing capacities cannot be distinguished from what we already do by appeal to a treatment/enhancement distinction. (On Sandel’s view, I argued, radically longer life spans might turn out to be treatments because they stop impediments to normal gifts. On 
Schwartz's view, they turn out to be enhancements because they do not deal with normal dysfunctions. But neither author's analysis distinguishes such life lengthening from what they already consider permissible.)

(b) Now consider Schwartz's value analysis. He begins by saying that we should value a life without dysfunction and that it is morally superior not to reject the normal, but he then concludes by saying that it is not unreasonable to sometimes value a life with dysfunction (such as infertility) over a life without it. This, of course, implies that it can be right to reject the normal (either in end state or in mechanism leading to an end state). It seems that this could be true because it could be more important for a life to be good in nonnormal ways than for it to be normal. Hence, as Schwartz recognizes, it remains open that an enhanced life will be a greater good than a normal one, just as a life with a dysfunction can be a greater good than one without it. Furthermore, suppose a very small additional good gotten through abnormality (either dysfunction or enhancement) overrides any merit in normality. This would show that the merit in normality is very weak. $^{15}$

(c) Indeed, it is not clear that there is anything morally preferable about normality at all, or anything morally superior about preserving the normal than rejecting it. First, as noted in (a), according to Schwartz's analysis, some dysfunctions will be normal, and if we should value life without dysfunction, this means that sometimes we should not value the normal per se.

Second, recall that on Schwartz's analysis, normal means "functions so as to survive and reproduce at not too far from the mean for one's age and gender.” Presumably, survival and reproduction are worth valuing only if there is survival and 
reproduction of what is good; survival and reproduction of what is bad may be normal but not in any way good. Let us assume that what survives and reproduces is good, so that survival and reproduction are good. Why cannot superior-to-normal performance of these functions be better than normal function? For example, if it were normal for a species to just barely survive and reproduce, could the normal not have less value per se than the supernormal?

In order to see a general problem with using the normal as a basis for deciding when to alter characteristics, it helps to imagine what it would be right to do if, counterfactually, what were normal for us were what is, in fact, abnormal. So Down's Syndrome is considered abnormal for humans. But supposed it were normal for our species to have the intelligence of a Down's Syndrome person. Should we then think it wrong for the abnormally intelligent members of our species to alter the rest of us so that everyone had the sort of intelligence that is now considered normal? Presumably not, unless there were bad side effects of doing this. Those currently opposed to enhanced intelligence or enhanced memory point to the possible problems that might accompany these, such as not being able to forget and noticing too many defects in life. But suppose it were normal for our species to have the same intelligence as a Down’s Syndrome person or a weaker memory than we now have. Would we think it wrong for us to be altered so that we had levels of intelligence and memory now considered normal for us, despite some drawbacks relative to the lower states (as those lower states may involve blissful ignorance and a constant pleasant disposition.) Presumably not. The appeal to the value of the normal may just be a hidden way of supposing that there is a delicate balance between all our properties (and between our species and the rest of the world), and things 
might go for the worse overall for people if they made a local improvement to the normal.

I conclude that we have so far not seen why treatment but not enhancement justifies mastery over nature.

\section{Parental and Social Relations}

In this section, I shall examine Sandel's views on how enhancement may negatively affect our relations to persons, ourselves or others.

\section{A. One’s Children}

As noted above, Sandel paints with a broad brush in condemning enhancements due not only to genomic changes but to drugs and training. However, he also realizes that much of ordinary good parenting consists of what might ordinarily be called enhancement. Hence, he says the crucial point is to balance accepting love and transformative love. (Perhaps Sandel would want to apply this idea to changes adults seek to make to themselves as well.) He also seems to think of transformative love as concerned with helping natural gifts to flourish, framing and molding them so that they shine forth. (Similarly, in sport, he thinks that good running shoes help bring out a natural gift by comparison to drugs that would change a gift into something else.)

Let us first deal with the issue of balance. For all Sandel says, it remains possible that many more enhancements than he considers appropriate are ones that satisfy the balance between accepting and transformative love, for it is not clear what falls under “balancing.” For example, suppose my child already has an IQ of 160. Might balancing 
the two types of love in her case imply that I may (if this will be good for her) increase her IQ another 10 but not 20 points, even though a parent whose child has an IQ of 80 should not change her child as much as to also give her a 120 IQ, for this would err on the side of too much transformation?

An alternative to such a balancing view might be called Sufficientarianism. It could imply that there is no need at all to increase the first child's IQ and that in the second child's case much more transformation (in the sense of adding to natural gifts) than acceptance is appropriate in order to reach a sufficient level. Sufficientarians are not interested in perfection, though they want mastery as a means to getting sufficient goods.

Let us now restrict ourselves to Sandel's sense of transformation—bringing out natural gifts - and consider the ways in which this may be done. To the extent to which Sandel allows training and appliances to be used to transform gifts, nothing in his argument rules out using drugs or genetic manipulation that do exactly the same thing. So suppose that a certain amount of voice training is permitted to strengthen vocal chords. Would a drug or genetic manipulation that could strengthen vocal chords to the same degree also be permissible? If the argument Sandel gives does not alone rule out training, it alone will not rule out transformation by drugs or genetic means, because a gift is transformed to the same degree by each method. If appliances such as running shoes are allowed, why not genetically transformed feet that function in the same way? Ordinarily, such genetic changes would be considered enhancements, even if they are only traits in addition to one's natural capacities that allow the other natural capacity to flourish. An argument different from Sandel's, based on the possible moral difference in using different means to transform capacities, would be necessary to rule out drug or 
genetic means but permit training. As we have noted, Sandel treats training, drugs, and genetic manipulation on a par. This leaves his position open to endorsing many genetic enhancements (in addition to those that fall under treatment, as discussed in section III).

While Sandel rightly condemns excessive pressure to transform oneself and one’s children in a competitive society, especially if it is governed by shallow values, he does not condemn moderate training for worthwhile transformation. ${ }^{16}$ Unless he emphasizes a difference in means used, he should then permit moderate, worthwhile genetic transformations of natural gifts, even if not excessive ones driven by competitive pressures and/or governed by shallow values. (His argument against giving traits merely to give one's child a competitive advantage will also fail against traits that are good to have even if everyone gets them. ${ }^{17}$ For example, better eyesight or higher intelligence can raise the absolute quality of each person's life even if there is no change in relative advantage.)

Now consider one way in which Sandel may be wrong not to distinguish different ways of either transforming natural gifts or bringing about more radical enhancement by introducing major new capacities. Perhaps we should separate how we treat changes that are made before a child exists (what I shall call ex ante changes) from those that are made once a child exists (what I shall call ex post changes). The former are primarily genetic, while the latter will include drugs and training.

Love, it has been said, is for a particular. Consider love for an adult. Before we love someone, we may be interested in meeting a person who has various properties, such as kindness and intelligence. When we meet such a person, we may be interested in him or her rather than someone else because he or she has these properties. However, though 
it is through these properties that we may be led to love this particular person, it is the particular person that we wind up loving, not his or her set of properties. For if another person appears with the same set of properties that does not mean that we could as easily substitute him or her for the person we already love. Even if the person we love loses some of the properties through which we were originally led to love him or her (e.g., his beauty), we would not necessarily stop loving the particular person we love (Nozick 1977).

It seems then that when we love a particular person, this involves much of what Sandel calls accepting love. If we do seek transformation in the properties of the person we love, this may be because of moral requirements he would fail to meet without the properties, or because we want what is good for the person and can see a way of achieving it that is consistent with what he wants for himself. By contrast, before a particular person whom we love exists (just as before we find someone to love), it is permissible to think more boldly in terms of the characteristics we would like to have in a person and that we think it is excellent for a person to have, at least so long as these characteristics would not be bad for the person who will have them and are consistent with respect for persons.

The latter side-constraint -- respect for persons -- could even conflict with doing what is best for someone. For example, suppose peace of mind and equanimity are goods for a person. Nevertheless, insuring their presence by modifying someone so that she is self-deceived about awful truths or about her duties to others would be inconsistent with taking seriously that one is creating a person, an entity worthy of respect. Both the sideconstraint of respect and the side-constraint of concern for the person's best interests 
could conflict with what has been called a "genetic supermarket," wherein parents choose traits for offspring according to their own preferences. I agree with Sandel that such a consumer model is out of place when creating persons. Sandel says, "Not everything in the world is open to whatever use we may desire or devise” (2004, 54). This is certainly true of persons.

Still, before the existence of a person, there is no one with certain characteristics that we have to accept if we love him and do not want to impose undue burdens necessary for changes. Hence, not accepting whatever characteristics nature will bring but altering them ex ante does not show lack of love. Nor can it insult or psychologically pressure a person at the time changes are made the way ex post changes might. This is because no conscious being yet exists who has to work hard to achieve new traits or suffer fears of rejection at the idea that they should be changed. Importantly, it is rational and acceptable to seek good characteristics in a new person, even though we know that when the child comes to be and we love him or her, many of these characteristics may come and go and we will continue to love the particular person. This is an instance of what I call the distinction between "caring to have” and "caring about.” That is, one can know that one will care about someone just as much whether or not she has certain traits and yet care to have someone, perhaps for their own sake, who has, rather than lacks, those traits (Kamm 2004). ${ }^{18}$ Sandel says that “parental love is not contingent on talents and attributes a child happens to have" (Sandel 2004, 55). This is true because love is for a particular about whom one cares, but this is consistent with caring to have and seeking better attributes in a person-to-be, at least ex ante. 
Applying what I have said to the issue of enhancement suggests that even if transformative and enhancing projects should be based primarily on what is best for the child-to-be, this is consistent with trying to achieve ex ante a child with traits that will be desirable per se, so long as they will not be bad for the child and are not inconsistent with respect for persons. By contrast, ex post enhancement may have to be more constrained for it could involve psychological pressure on the child and lead to fear of rejection. However, even ex ante enhancement, given that the child knows about it ex post, can lead to some forms of psychological pressure. For example, if you know that you have been deliberately given a talent for music, you may feel under pressure to use it, though you would prefer not to. ${ }^{19}$ It might be suggested that we could avoid this problem by modifying the person-to-be so that the person would always prefer the other traits that we have given them. But doing this would be inconsistent with respect for persons, for the exercise of independent judgment should not be restricted; if anything, it should be enhanced. An alternative way to reduce pressure ex post is to provide traits that either add value simply in being present (such as better eyesight) or by increasing options for someone (for example, to either play or not play music).

Drawing a distinction between the methods of ex ante and ex post “designing” does not, however, put to rest different sorts of objections to even nonpressuring ex ante enhancements. Let us consider some.

(1) First, Sandel thinks that people are not products to be designed. I agree that people are not products in the sense that they are not commodities, but rather beings worthy of concern and respect in their own right. But I do not think this implies that it is morally wrong to design them. Consider first if it would be acceptable to redesign 
oneself. We are accustomed to people having replacement parts, such as knees and transplants. Suppose when our parts wore out, we were offered alternatives among the new ones. For example, teeth of various colors, joints that were more or less flexible, limbs that were longer or shorter, It might well make sense to make selections that involved redesigning ourselves. Similarly, if we could replace brain cells, it might make sense to choose ones that gave us new abilities. This would also be redesigning ourselves.

Now consider creating new people. We already have much greater control over the timing of pregnancy, over whether someone can conceive at all, and over which embryos are chosen (via preimplantation diagnosis) for development. Rather than humility, we have justifiable pride in these accomplishments. Suppose that we each had been designed in detail by other persons. (We all know that the story about the stork bringing babies is a myth. Just suppose that sexual reproduction and the natural lottery in traits are also myths, and we have really all been designed.) Presumably, we would still be beings of worth and entitled to respect. But might it be that although a being retains its high status despite such an origin, it is inconsistent with respect for persons to choose such a designed origin for them? (Analogously, a person retains his status as a rights bearer even when his rights are violated, but it is not, therefore, appropriate to violate his rights.) To answer this question, imagine that the natural way of reproducing required that important properties be selected for offspring, otherwise they would be mere lumps of flesh. Surely, selecting properties would be permissible. If this procedure were working well, would we be nevertheless obligated, out of respect for persons, to introduce a lottery based on chance as a way for definite properties to come about? I do 
not think so. Hence, I conclude, the designing of persons is not per se inconsistent with respect for persons. ${ }^{20}$

(2) Some associate designing people with engineering them rather than raising them and letting them grow, and criticize designing for this reason. ${ }^{21}$ However, I do not think these necessarily are contrasts. One could put together the innate mechanisms that are now present in people at birth (thus engineering them) and then they could grow and be raised as they are now. Some may think that putting together a living being according to a design would threaten our ability to worship, revere, and love it; we could not have what might be called the “ooh-response.” Worse, the idea of putting something together might suggest that there is nothing wrong with taking it apart (thereby destroying it). But many things we revere and love are created by us, and not just as the result of acts of inspiration. Works of art and craft, literature, hybrid plants and animals are composed, revised, put together in parts that we can come to understand completely. And yet we can respond to these as more than the sum of their parts, revering and loving them. Of course, such entities are not persons and do not have the moral status of persons. But that is because they do not have the properties of persons. If we gave such properties (as rationality and emotion), the worth that supervenes on them, and the response to the worth, would be present, too.

Crucially, it is a mistake in criticizing enhancement to focus on its occurring by a mechanical, piecemeal construction process (engineering) for enhancement does not essentially involve it. Consider that parents typically wish and pray that their children be good people, have good judgment and worthwhile capacities. Suppose that wishing made it so and one could be assured that one's prayers would be answered. This would be a 
means of enhancement. Should parents then not engage in such efficacious wishing and praying, even if they wish and pray for the right things? ${ }^{22}$

(3) A third general objection to ex ante designing asks, if someone wants to have a child, should she not focus only on the most basic goods, such as having a normal child to love? If so, then if she focuses on achieving many superior qualities, does that not show that she is interested in the wrong things in having a child? To answer this worry, consider an analogy. If the primary concern for a philosopher in getting a job should be that she be able to do philosophy, does that mean that it is wrong to choose between possible jobs equally satisfying that characteristic on the basis of higher salary? If not, why is the search for properties other than the basic ones in a child wrong, when the basic ones are not thereby put in jeopardy? (Of course, in the case of the child-to-be, unlike the job, the enhanced properties are usually to be for its benefit, not only for those doing the selecting.)

Furthermore, searching for more than the basics does not by itself imply that if one could not achieve those enhancements, one would not still happily have a child who had only the basics, and love the particular person she is. In this way, too, seeking enhancement is consistent with being open to the unbidden. What about disappointment? It is true that the more one invests in getting enhancements, the more resources one will have wasted if the enhancements do not come about; the lost resources, rather than the child one has, could be a source of disappointment. There may be disappointment for the child when enhancements fail—-that one could not bring about something good for it. But that is different from disappointment in the child. Further, while someone who would refuse to have a child without enhancements might thereby show that he did not care 
about the core reasons for having a child, even this does not show he is unfit to be a parent. For he could still come to love the child if he actually has it, through attachment to it as a particular (as described above).

(4) I have argued that often ex ante changes would be preferable to ex post changes because there would be less pressure on, and less opportunity for feelings of rejection by, the child. But a fourth concern about ex ante enhancements is that a parent will simply have greater control over the child's nature, whether she seeks it or not. (As Sandel agrees, this does not mean that the child will have less control, for it is chance, not the child, that will determine genetic makeup, if other persons, such as parents, do not. Nor does it mean that the issues of "designing” children and parental control are not separable in principle. For if someone other than the parent designed the child, relative to the parent the child would still be part of the unbidden.) Is it possible that if we could produce a certain desirable trait in someone equally well and as safely by genetic means or by ex post drugs or training, we should prefer the latter means because they give the child greater freedom relative to its parent?

Consider the following argument for this position ${ }^{23}$ : Suppose a parent is told that its fetus has a gene that will make it aggressive to a degree that is undesirable from the parent's point of view though not outside the normal range. The gene could be altered so that the person that will develop will be less aggressive. Alternatively, the person who will develop could take a drug through her life that will successfully reduce the aggressiveness caused by the gene. The latter course is to be preferred, the argument maintains, because when the child reaches maturity she can decide to stop taking the drug, if she decides that she prefers being a more aggressive person. By contrast, if her 
parents had made the genetic change, the claim is, she would not have this freedom to choose to be more aggressive.

This argument does not succeed, I believe. For it rests on the assumption that a genetic trait for aggression can be altered perfectly well by taking a drug. But if that is so, then it is also possible that the revised genetic disposition to be less aggressive can be altered by taking a drug that increases aggressiveness. Hence, the child whose parents made the genetic change could have the same freedom to alter her temperament as the child who was not so altered. On the other hand, if drugs could not alter traits as well as genetic modification, this would leave each child with a genetic makeup either given by nature or by a parent; it would still be unfree to modify itself by drugs ex post.

Of course, many would reject both ex ante genetic and ex post drug modification, rather than modification by effort or exercise. The struggle involved in effort and exercise is said to have moral value. But this suggests that it would be better if most members of our species did not have the genetic tendency, that they in fact have, toward fellow feeling, but rather, like the exceptional few currently who are highly aggressive, had to produce fellow feeling in themselves by great effort. But this would not be better. Similarly, imagine that following purely imaginary case. Your high intelligence and natural grace, which in someone else would be due to an enhancement, is your normal luck in life's lottery, and it is due to a large degree to your genetic makeup. Then something goes wrong with your genes and you are losing your high intelligence and grace. Would you now be thankful that you had the freedom to decide whether or not to work extra hard to compensate for the loss or even take many drugs each day to correct for your genetic failings? Or would you prefer genetic surgery so that your genes worked 
the way they always had? Presumably the latter. Here the strategy (used earlier as well) is to imagine that what is normally genetically controlled, either for the species or just for you (as a naturally superior person) is absent. Then we consider whether there is anything offensive per se in relying on genetic manipulation to restore or produce the desirable trait.

In numerous areas of life, persons now justifiably stand in relations of control over other people where once chance ruled. The important thing is that this be done justly and well. Furthermore, if we choose certain characteristics in offspring, the balance of control over the child's life may shift to the child rather than the parent, even if the child does not have the capacity to further alter the characteristic ex post.. What I have in mind is that if we could ensure that a child had such enhancing traits as self-control and good judgment, then the child would be less, not more, likely to be subject to parental control after birth. This is what is most important.

(5) A fifth concern is that if each parent individually tries to do what is best for its child, all parents will end up making the situation worse for all their children. To avoid this prisoner's dilemma situation, some rule that coordinates the choices of parents seems called for. $^{24}$

The primary conclusion of this subsection is that Sandel does not show that seeking to enhance children, especially ex ante, is inconsistent with a proper balance between accepting and transforming love.

B. Social Justice 
Finally we come to Sandel's views on the connection between enhancement and the twin issues of burdens of responsibility and distributive justice. If people are able to enhance themselves or others, can they not be held responsible in the sense of being blamed for not giving themselves or others desirable characteristics? Not necessarily, for one does not have a duty to do everything that could make oneself or someone else better, and if one has no duty, then one is not at fault in not enhancing and so not to be blamed. Even if one has certain duties, for example, to be the best doctor one can be, and taking certain drugs would help one to perform better, it is not necessarily one's duty to take the drugs. One could retain a right not to alter one’s body even in order to better fulfill one's duties as a physician. Hence, one need not be at fault even if one does not do what will help one perform one's duties better. But retaining the right not to alter one’s body does not require making such alterations impermissible for anyone who wants them. Of course, if the characteristics one will have must be decided by others (for example, one's parents), then one could not be blamed for causing or not causing the characteristics, as one could not have directed one’s parents’ behavior.

What about cases in which one can be blamed for a choice not to enhance? Thomas Scanlon has emphasized that one can hold someone responsible for an outcome in the sense of blaming him for it without thereby thinking that it is also his responsibility to bear the costs of his choice. ${ }^{25}$ These are conceptually two separate issues. For example, suppose someone is at fault for acting carelessly in using his hairdryer. If he suffers severe harm and will die without medical treatment, his being at fault does not mean that he forfeits a claim on others he otherwise had to free medical care. 
By contrast, Sandel thinks that the issue of responsibility for choosing to have or to lack certain characteristics is intimately related to how much of a claim we have against others for aid. However, he is not always clear in distinguishing the role of choice from the role of mere knowledge of one’s characteristics. For example, in discussing why we have insurance schemes, he seems to imply that even if we had no control over our traits but only knew what they were (for example, via genetic testing), we would lose a claim against others to financially share the costs of our fate. For, if people knew they were not at risk, people would not enter into insurance schemes that mimic solidarity. So Sandel's argument based on solidarity against enhancement seems to be an argument against knowledge of genetic traits as well as against control of them. But those who urge us to use a veil of ignorance in deciding whether and when we should share others' burdens (via allocation of resources) are, in effect, saying that even if we have knowledge of one another's traits, there are moral reasons for behaving as though we lack the knowledge.

Let us put aside the issue of blameworthiness for, and the effect of mere knowledge of, traits. How should the mere possibility of making choices that determine one’s traits affect responsibility for bearing costs for the outcome of choices? Sandel here seems to share with some philosophers (known as luck egalitarians) the view (roughly) that if we have not chosen to have traits but have them as a matter of luck (or other people's choices), the costs of having them should be shared. However, if we choose the traits (by action or by omitting to change them if we can), then even if we do not in any deep sense deserve to have made this choice, there is no reason for the costs of having the traits to be shared. (According to some luck egalitarians, however, we may choose to buy 
insurance that will protect us against bad choices.) Sandel says he cannot think of any better reason for the well-off to help those who are not well off except that each is not fully responsible for his situation. (It is important to remember that some do not find this a compelling reason for sharing with others. Robert Nozick, for example, argued that one could be entitled to what followed from the exercise of traits that one was not at all responsible for having. ${ }^{26}$ )

Contrary to Sandel, it seems that often we want to give people new options without taking away from them help they would have gotten from others when they had no control over their fates. One example given above involved someone whose choice to use a hairdryer should not lead to his forfeiting aid to avert a major disaster. Similarly, if someone for reasons of conscience refuses to take advantage of the option to abort a difficult pregnancy, we do not think that she should forfeit medical care simply because she could have avoided the need for it. In many cases, arguments for the duty to aid others seem to have more to do with respect and concern for persons than with whether they have or have not gotten themselves into whatever situation they are in. Of course, in cases I have been considering, someone chooses in a way that leads to a bad outcome he does not per se choose. But recall that Kant thought we had a duty to help people pursue even the ends they themselves had deliberately chosen because people matter in their own right, rather than because they could not be held responsible for outcomes or because it was only the unwilled consequences of their choices with which we were asked to help.

It may throw further light on the effect of the option to enhance on shared responsibility to consider the effect on shared responsibility of the option to treat. Sandel, 
of course, is not against giving individuals the option to treat or prevent their diseases. This is so despite the fact that one might construct an argument concerning the option to use treatments and preventions parallel to the one he constructs for the option to use enhancements. That is, someone might say that giving the option to use treatments and preventions will destroy the willingness of the healthy to aid the sick who had the option to avoid illness by earlier treatment or prevention but did not, especially when the healthy attribute their own health to their choice to use such earlier interventions. The fact that this is not a successful argument against spreading the option of treatments should lead us to question its success against enhancements.

Now, suppose it were true that to some degree, as we increase the range of individual choice, we limit the claim of a person to the assistance of others. (For example, choosing to be or remain paralyzed, given the option of a cure, because one preferred that sort of life might be considered an "expensive taste,” and public assistance to make such a life go as well as an unparalyzed life might justifiably be denied.) Does this mean that we will have lost valuable solidarity? If it is appropriate that people who have equal opportunity to choose enhancements but decline to do so bear more responsibility for their condition, then the moral status of solidarity will have changed; it will no longer be the only correct, valuable, and virtuous response that it is in other circumstances. If so, it's absence will not necessarily be bad. Furthermore, it is still true that, if having the option to enhance leads many people to improve themselves or others, there will be fewer instances of people who are badly off, hence fewer who require the assistance of others. For example, rather than redistributing wealth that only the talented can produce in a certain environment, each might have a relevant talent and so have the opportunity to be 
more productive in that environment. Furthermore, each person would not only have the material benefits that can be redistributed from some to others. Each person could have the intrinsic rewards of exercising abilities and talents, something that cannot be redistributed.

Let me conclude this section by noting that if Sandel were concerned with the increased burden of responsibility for one's traits and one's children's traits, not at the individual level but at the social level, there would be no way to completely avoid the burden of increased responsibility. For suppose a society or species knows that it could change traits of its members by using or developing genetic or chemical means. Those who decide that the society will not use these means will be to some degree responsible for the absence of enhanced traits. (This is so even if some other individuals will not be responsible because others in the society made it impossible for them to have a choice about use of the means at the individual level.) However, society will be to blame for failures to improve people only if there were no good reasons not to engage in enhancement. Perhaps preventing individuals from becoming responsible for individual outcomes could be offered as a reason. But can preventing increased social responsibility for outcomes be offered as a reason, if society will already have increased responsibility, given that it is responsible for whether to allow use or development of enhancement techniques? Possibly, this reason would still be available, if a distinction could be drawn between degrees of responsibility, so that there is less social responsibility for a genetic trait if society chose to let chance determine it than if society actually selected the trait. The primary conclusions of this subsection are that Sandel does not successfully show that we should limit options to enhance ourselves or others as a way of ensuring a 
right to social assistance. I suspect that Sandel may just believe that people should be able to call on the assistance of others when they need it regardless of many individual choices they make. Such a belief could account for the subterfuge of eliminating the possibility of individual choice for enhancement as a device to sustain a duty to aid. (This would be somewhat like the strategy of pretending that one cannot figure out what share of an outcome each person is responsible for producing, as a way of insuring equal shares of a social product. The fact that one seeks such a subterfuge suggests that one simply believes that equal shares are right regardless of differential input.) It would be better to just argue that the possibility of choices made through enhancement does not always eliminate a duty of assistance rather than using the subterfuge. .

\section{Conclusion}

Sandel focuses on the desire for mastery and the unwillingness to live with what we do not control as objections to enhancement. (He also focuses on the more contingent issue of the misuse of the ability to enhance ourselves and others that is likely to occur in a competitive environment, especially governed by shallow values.) I have argued that what is most troubling about enhancement is neither that there will be people who desire to have control over nature, offspring, and themselves, nor unwillingness to accept what comes unbidden. However, I do think there are major problems with enhancement. Some are the ones Sandel puts to one side. Given our scarce resources, where should enhancement be on the list of things to do? Will there be a fair distribution of benefits of enhancement? Could we really safely alter a system as complex as a person (by genetic 
enhancement or treatment) without making disastrous mistakes? Consider the last point further.

It has been pointed out that in a complex system such as a human being, whose parts are densely interdependent, even small alterations can have unexpected bad effects. Extreme caution, at least, seems called for. ${ }^{27}$ Genetic manipulation has been contrasted with surgery or taking drugs in this respect. (Sandel's complaint holds equally against all these means of enhancement, and he deliberately puts to one side issues of differential safety to focus on an objection that he thinks would be present even if there were no safety issues.)

In rebuttal, it might be suggested that genetic changes to individuals that would not affect their offspring could be made no less safe for the individual and the species than use of drugs. For in using drugs or even surgery, one usually thinks that one can, at least often, stop a change and revert to one's original condition if things go badly. If genetic changes could also be reversible, or at least counteractable in some way, then the risk of using them would also be diminished.

Further, it might be pointed out that the dense interdependence of the parts of our system also creates great risks even with therapeutic interventions, so it would be good to know specifically why enhancements present greater potential threats. And then there is the interdependence of human beings with the rest of the world. Is it not possible that treating a defect in individuals that eliminates the normal presence of such defects in the human species would upset some delicate balance between our species and the rest of nature? Yet we do not let this possibility interfere with our search for treatments. 
Another issue in enhancing, I think, is that we will be doing it, and so our lack of imagination as designers may raise problems. That is, most people's conception of the varieties of goods is very limited, and if they designed people their improvements would likely conform to limited, predictable types. But we should know that we are constantly surprised at the great range of good traits in people, and the incredible range of combinations of traits that turn out to be good. For example, could we predict that a very particular degree of irony combined with a certain degree of diffidence would constitute an interesting type of personality? In section IV A, I mentioned the view that potential parents should focus on having children with basic good properties rather than seek improvements beyond this. Oddly, the “lack of imagination” objection to enhancement I am now voicing is based on a concern that in seeking enhancements people will focus on too simple and basic a set of goods.

How does the lack of imagination objection relate to Sandel's view that an openness to the unbidden (excluding illnesses) extends the range of our sympathies? One construal of his point is that if we have no control, we are forced to understand and care about people, as we should, even when they are difficult and nonideal. By contrast, the lack of imagination objection emphasizes that when creatures of limited imagination do not design themselves and others, they are likely to extend the range of their appreciation of great positive goods because the range of such goods is likely to be larger. Fifty years ago, a parent who would have liked to design his child to have the good trait of composing classical music, could not have conceived that it would be good to have a child who turned out to be one of the Beatles. (To have conceived it, would have involved creating the Beatles’ style before the Beatles did.) The lack of imagination 
objection is concerned that too much control will limit the number and combination of goods from what is possible. Hence, at least in those cases where greater goods are more likely to come about if chance rather than unimaginative choice is in control, the desire for enhancement will militate against control.

Finally, if the controlled selection of enhanced properties is a morally acceptable means, at least sometimes, what are the good ends to which it could safely be used? Presumably, if it were at all possible, it would be a safe end to enhance our capacities to recognize and fulfill our moral duties. Recognizing and fulfilling moral duties is a side constraint on the exercise of any other capacities and the pursuit of any ends. There is no point in worrying that having such moral capacities would interfere with unimagined goods. For if such moral capacities interfere with other goods, this just means that those other goods are not morally permissible options for us.

\section{References}

Ashcroft, R. E., and Gui, K. 2005.' Ethics and world pictures in Sandel and Kamm'. The American Journal of Bioethics, 5(3): 19-20.

Coors, M., and Hunter, L. 2005. 'Evaluation of genetic enhancement: Will human wisdom properly acknowledge the value of evolution?' The American Journal of Bioethics, 5(3): 21-22.

Kamm, F. M., 2004. 'Deciding whom to help, health-adjusted life years, and disabilities', in Public Health, Ethics, and Equity, eds. S. Anand, F. Peters, and A. Sen, . Oxford: Oxford University Press, 225-242. 
Liao, S. M., 2005. 'Are “Ex ante” enhancements always permissible?’ The American Journal of Bioethics ,5(3): 23-25.

Martin, A., and Peerzada, J. 2005. 'Impermissible attitudes, impermissible enhancements'. The American Journal of Bioethics, 5(3):25-27.

Miller, F., and Brody, H. 2005. 'Professional integrity and enhancement technologies'. The American Journal of Bioethics, 5(3): 15-17.

Nozick, R., 1977. Anarchy, State and Utopia. New York: Basic Books.

Robert, J. S., 2005. 'Human dispossession and human enhancement'. The American Journal of Bioethics 5(3):27-29.

Sandel, M., 2004. ‘The case against perfection’. Atlantic Monthly 293(3): 51-62.

Scanlon, T., 2000. 'Intention and permissibility I'. Proceedings of the Aristotelian Society. Suppl. 74: 301-317.

Scanlon, T. Unpublished article. 'Blame’.

Schwartz, P. H., 2005. 'Defending the distinction between treatment and enhancement'. The American Journal of Bioethics, 5(3): 17-19.

Shiffrin, S., 1999. 'Wrongful life, procreative responsibility, and the significance of harm’. Legal Theory, 5(2): 117-148.

Strong, C., 2005. 'Lost in translation: Religious arguments made secular'. The American Journal of Bioethics, 5(3):29-31.

Thomson, J. J., 1990. The Realm of Rights. Cambridge, Mass.: Harvard University Press. Thomson, J. J., 1999. 'Physician-assisted suicide: Two moral arguments'. Ethics, 109(3): 497-518. 


\section{Notes}

1 This article is a revised version of "Is There a Problem with Enhancement?" American Journal of Bioethics [AJOB], 5(3): 1-10. It incorporates some of my responses to the very useful commentaries on that article. The commentaries appear in the same issue of AJOB and my complete responses appear at the AJOB website. It also incorporates some of my responses to Sandel’s helpful commentary on my presentation of parts of this article at the Inaugural Conference of the University Wide Program on Ethics and Health, Harvard Medical School, Nov. 19, 2005. I am also grateful to audiences at that conference, at the UCLA Program in Genetics and Society, and at Bowdoin College.

2 Notice that not deliberately causing something is not the same as not causing it. For example, a parent may cause his child's IQ to move down from 160 to 140 by inadvertently eating improperly during pregnancy. This reduction is unbidden, though caused by the parent. It is in part because we might be causally responsible for making things worse than they could naturally be, that some may think that we have a duty to achieve at least the knowledge of life processes that prevents our interfering with naturally occurring goods.

3 I shall return to this point below.

4 Judith Thomson $(1990,1999)$ has argued that intention never matters to the permissibility of action. Thomas Scanlon (2000) makes a somewhat more limited claim.

$5 \quad$ As emphasized by Paul Litton and Larry Temkin. 
6 This was emphasized in Martin, A, and J. Peerzada (2005). The discussion that follows is my response to their views and some of their cases.

7 Julie Tannenbaum, however, pointed out (in discussion) that the equal rights of nonehanced persons may depend not only on their properties qua persons but possibly on the fact that the properties of the enhanced would make them different only in degree but not in kind. For suppose we were creating gods. It might then be an open question whether persons would have fewer negative and positive rights in relation to gods than in relation to other nongod persons.

8 Of course, it is possible in a society that only its leaders have certain particular intentions or dispositions and they arrange rewards and punishments so that individuals in the society fulfill the leaders' aims without necessarily sharing their aims or dispositions. However, I do not think Sandel deals with such a scenario.

9 This was part of his response to me on Nov. 19, 2005. The following section C summarizes our discussion on that occasion.

10 Carson Strong emphasizes that the idea of a gift requires a giftgiver and that, therefore, from a secular perspective where we do not assume a God, it is not literally true that children or naturally occurring good properties are gifts, as Sandel speaks of them (Strong (2005).) However, Strong himself notes that Sandel might simply emphasize the role of chance and good luck—as in a Rawlsian natural lottery—and use a metaphorical sense of giftedness. Strong also suggests that literal giftedness would come into the world, in the secular point of view, if parents did deliberately give good traits to their offspring. But "gift" has another connotation that militates against this conclusion to some degree, I believe. For a gift suggests some good that one gives beyond the call of duty; the 
recipient is not entitled to receive it. Children, however, might be entitled to certain enhancements, let alone certain treatments, from their parents and then those would not be gifts in the strict sense.

11 Similarly, the human and the good are distinct conceptual categories. Human traits (such as arrogance) could be bad, and inhuman altruism could be good.

12 In discussion on November 19, 2005.

13 As described in P. H. Schwartz (2005).

14 F. Miller and H. Brody (2005) at one point attempt to fit induced infertility by contraception into a narrow notion of medical care by suggesting that even though it is an enhancement, it prevents clear medical risks involved in pregnancy and mental health problems associated with unwanted births. But suppose (counterfactually) that pregnancy had no medical risks and hormonal changes in women made it possible for them to always adjust psychologically to each additional child. It could still be true that a woman could sometimes have a better life if she did something besides have another child, and she should use contraception to achieve that good. Here the provision within medical care of contraception, which itself has some medical risks, would be unrelated to avoiding any health risks. Yet it could be appropriate for a doctor to prescribe it.

15 There is also another sense in which enhancement is more important than normality-preserving treatments: We are all willing to risk some illness by spending money on life-enhancing activities (such as education) rather than on cures for disease.

16 Hilary Bok emphasized this point. 
17 This point was emphasized by Marcia Angell in discussion.

18 I previously argued for this distinction in Kamm (2004) when discussing the compatibility of (a) a disabled person caring about his life as much as a nondisabled person cares about his life, and (b) a disabled person caring to have a nondisabled life rather than a disabled one.

19 I owe this point to Seana Shiffrin

20 Notice also that an alternative of designing the gene pool so that only enhanced options are available is compatible with chance determination of the properties of any given individual.

21 R. E. Ashcroft, and K. Gui (2005).

22 It is true that when we pray and wish now, we may hope there is a superior being who will grant our prayers only when they are appropriate. (This is the point of the "if it be Thy will” part of the prayer.) But this can signal our concern that we may not really be enhancing in getting what we want. I discuss this problem of limited wisdom or imagination in the last section of this article.

23 Presented by Anja Karnein and based on one by Jurgen Habermas.

24 Larry Temkin emphasized this point. A sixth objection to some ex ante enhancements was raised by Matthew Liao (in Liao (2005)). Liao argues that some ex ante enhancements (which I contrast to ex post enhancements) are impermissible, even though the person does not yet exist, and this is not because of any property the person eventually comes to have, but because of the morally dubious intention of the enhancer (2005, 2-3). For example, suppose someone sex-selects a female child for the purpose of selling her into prostitution, or (in my own illustration) creates a brain-enhanced child for the purpose of exhibiting him 
in a zoo. However, each creator then comes to love the child for its own sake and treats it properly. Liao notes that I suggest that characteristics sought ex ante should not be bad for the person who will have them and should be consistent with respect for persons. But being female or brain-enhanced is not bad for a person or inconsistent with creating a person worthy of respect. Hence, he thinks, it is not because of the properties that would be given, but because of the further intentions of the agents that their acts are wrong $(2005,5)$.

He also thinks that I mean to imply that properties that are morally undesirable (such as being subject to self-deception) make persons no longer worthy of respect, but he counters that having a morally dubious property does not do this. Yet, he agrees, it is still wrong to ex ante do what gives this property to someone. This cannot be, he thinks, because of what the property is in itself, or because the person could have existed without the property and been better. The latter claim, Liao thinks, cannot be true because an individual comes into existence at the same time as his ex ante chosen properties and the person without that property would have been a different person. Hence, the person now in existence with the property cannot complain that he was harmed by being given the property, assuming his life is worth living. Liao concludes from all this that the wrongness of giving such a property lies in the morally dubious intentions of the agent $(2005,6)$.

I do not think Liao's arguments succeed. First, consider the person who creates a female child intending to make her a prostitute, or a brain-enhanced person intending to exhibit him. I would say that the first creator is attempting to 
create a prostitute and the second an exhibition animal, and each of these properties is not one that persons should have. But suppose that an agent attempting to create someone with these properties cannot succeed, perhaps because he is bound to love each of the people he creates. Then I would say that his actual act of creating the people is not impermissible, though what he attempts to do (make prostitutes or exhibition animals) is impermissible. I would say that a morally worse event or act has taken place in virtue of the bad intention prompting his act, but this does not mean his act is impermissible.

Second, contrary to Liao, I do not mean to imply that giving a person a morally dubious property makes the person not worthy of respect. The person just remains someone worthy of having properties more appropriate to his status. Similarly, violating someone's rights can be inconsistent with respect for a person without in any way altering his status as a creature worthy of respect. Most disturbing, from the fact that a naturally disabled person remains a person worthy of respect, Liao concludes that the wrongness of deliberately creating a disabled person cannot be due to his winding up with the property of being disabled; the act must rather be wrong because of the motivation or intention of the agent. But surely it can be wrong to do what gives people properties that do not diminish their worth but just make their lives much worse for them to live, regardless of one's motivation or intention (for example, as a mere side effect of some useful act).

Now consider Liao's arguments based on identity considerations for the claim that an act creating a person with a certain property cannot be wrong 
because of the property. First, it is not always true that a person would not have existed at all if he had not existed with a certain property. For not all properties are essential properties and we could imagine having changed a given embryo for the better by affecting one of its a nonessential properties. Then that person could have been better than he actually is. Now consider the cases in which a different person would have been created if a property had been different-perhaps because an essential property is at issue. Liao says that in such a case, the person created with the nonoptimal property cannot complain that he is worse off than he might otherwise be. But it does not follow from this that we cannot say it is impermissible to have created a person with the property rather than someone else without the property, in virtue of what the property is. Hence, we need not refer to the intentions of the creator in judging the permissibility of his act.

25 In Thomas Scanlon, What We Owe to Each Other (Cambridge, Mass.: Harvard University Press, 1999).

26 See his Anarchy, State, and Utopia. Unlike luck egalitarians, Rawlsians may think that it is the fact that a particular social structure is, to a large degree, responsible for what sort of fate in life one’s genetic properties will yield that shared responsibility is justified. This is by contrast with bad luck that is the result of socially unmediated natural effects, for which a Rawlsian might think that shared responsibility is not a matter of justice. Notice that the problem for shared responsibility of outcomes (solidarity) with which Sandel is concerned is different from another problem that concerns J. S. Robert in Robert (2005). Robert is concerned that giving people the choice of enhancement before we take care of 
the many who lack basic necessities is already to show a lack of solidarity with others $(2005,6)$. The fact that we think of doing this tends to weaken Sandel's view that we are more likely to help people when our traits are not chosen. For they are not chosen now, and yet, as Robert sees it, we are unwilling to share with the needy now. But does seeking enhancement indicate a lack of solidarity? Robert himself thinks that it is only psychologically realistic to demand moderate self-sacrifice from each of us. But such a degree of self-sacrifice may be consistent with seeking enhancement for oneself while others are in need of basic necessities. Further, if we were trying to provide the autonomous choice of enhancement to everyone, even though this is not what many need most, this itself would be an instance of solidarity, in the sense that we care for others as well as ourselves. And if it were unrealistic to expect us to sacrifice a great deal for others, helping them to enhance themselves at small additional cost (if this were possible) may leave them better off overall than if there were no opportunities for enhancements. However, none of this would solve the problem of solidarity with which Sandel is concerned, as that only arises after people have the option of autonomously enhancing themselves, and thus are thought to both lose a claim to further assistance and to lose the motivation to assist.

27 M. Coors and L. Hunter,. 2005. 